\title{
Percepção, cognição e aprendizagem socioambiental em unidade de conservação
}

\author{
Bernadete Machado Serpe ${ }^{1}$ \\ Ademir José Rosso ${ }^{2}$ \\ Brigido Vizeu Camargo ${ }^{3}$
}

Resumo: $O$ artigo analisa o envolvimento da percepção na construção de conhecimentos e práticas socioambientais numa trilha interpretativa (TI) de uma unidade de conservação (UC). O objetivo foi evidenciar a possibilidade de aprendizado em uma TI, provocado por conflito cognitivo do visitante ao problematizar o ambiente. Fundamentado na Psicologia e Epistemologia Genética (PEG) piagetiana, o artigo discute a construção do conhecimento mediada por conflitos e desequilíbrios cognitivos. As informações coletadas referem-se a vinte e um sujeitos acompanhados e entrevistados ao longo da TI. A análise das informações ocorreu de forma qualitativa e quantitativa por meio de análise de conteúdo e da classificação hierárquica descendente feita pelo software ALCESTE. As análises realizadas na ótica PEG demonstram que as informações coletadas afirmam o papel do conflito cognitivo na re/des/construção das percepções em atividades de educação ambiental.

Palavras-chave: Construção do conhecimento. Aprendizagem socioambiental. Análise quantitativa.

\section{Perception, cognition and socioenvironmental learning in a conservation unit}

\begin{abstract}
This paper analyzes the involvement of perception in the construction of socioenvironmental knowledge and practices in an interpretive trail (IT) located in a conservation unit $(\mathrm{CU})$. The aim was to demonstrate the possibility of learning occurring in an IT as a result of the visitor experiencing a cognitive conflict by questioning the environment. Based on Piaget's Genetic Psychology and Epistemology (GPE), the paper discusses the construction of knowledge mediated by conflict and cognitive disequilibrium. Information related to twentyone subjects who were accompanied and interviewed along the IT was collected and analyzed in both qualitative and quantitative ways by means of content analysis and descending hierarchical classification, the latter being carried out by the ALCESTE software. The analyses carried out under the GPE perspective show that the collected information claims the role of the cognitive conflict in the $\mathrm{re} / \mathrm{de} /$ construction of perceptions in environmental education activities.
\end{abstract}

Keywords: Knowledge construction. Socioenvironmental learning. Quantitative analysis.

1 Doutoranda em Educação pela Universidade Estadual de Ponta Grossa. machado_be@yahoo.com.br

2 Professor da Universidade Estadual de Ponta Grossa.

3 Professor da Universidade Federal de Santa Catarina. 


\section{Introdução}

A criação de trilhas interpretativas (TIs) como percursos educativos que procuram aproximar o visitante do ambiente objetiva o desenvolvimento de atitudes e valores de respeito ao ambiente (MENGHINI, 2005; TABANEZ et al., 1997). Existem trilhas com guias para orientar o público a respeito das características do ambiente e trilhas autoguiadas que usam placas e/ou painéis descritivos em seu trajeto (MENGHINI, 2005). Temas como a água (TROGELLO; POLINARSKI, 2007) e o lixo (SOUZA; PRADO, 2007) e as histórias locais (SAMPAIO; GUIMARÃES, 2007) são constantemente abordados nesses espaços. Diante das inúmeras possibilidades, esta investigação aborda a TI na função de promotora de interações sujeito-meio ambiente e de experiências que habilitem o sujeito a perceber nessas interações a interferência humana.

As unidades de conservação (UCs) se constituem em espaços territoriais com proteção legal do patrimônio natural e dividem-se em duas categorias: unidades de uso sustentável, que têm por característica conciliar a conservação do ambiente e seu uso sustentável, e unidades de proteção integral, cujo objetivo é a preservação do ambiente, mas admitindo o uso indireto de seus recursos (BRASIL, 2007). Os parques estaduais, federais e municipais são classificados como unidades de proteção integral, logo, se caracterizam pela proteção dos ecossistemas naturais e pela viabilidade de realização de pesquisas científicas, além de atividades de Educação Ambiental (EA). No entanto, a visitação pública está sujeita às normas estabelecidas no plano de manejo ${ }^{4}$ de cada unidade (PARANÁ, 2002).

O presente texto apresenta uma versão das informações obtidas na dissertação "A aprendizagem socioambiental dos visitantes em Unidades de Conservação", realizada no Parque Estadual do Guartelá, município de Tibagi, Paraná, no ano de 2008. A trilha básica em que aconteceram as intervenções tem um percurso de aproximadamente dois mil e quinhentos metros e por meio dela o visitante se aproxima das particularidades da UC. No entanto, na maioria das visitas, o visitante não recebe informações suficientes sobre o ambiente, pois não há pessoal preparado para problematizar o processo de visitação.

O objeto de estudo da pesquisa é a aprendizagem socioambiental do visitante da TI de uma UC a partir da percepção ambiental. Os sujeitos são visitantes que estiveram na UC de maio a agosto de 2008 e que se disponibilizaram a participar da investigação. Para a seleção dos sujeitos optouse, como critério, por grupos constituídos de no mínimo duas pessoas e no máximo seis pessoas, visto que havia também a proposta de observação da integração dos sujeitos no grupo. Além disso, conforme um sujeito comunicava

${ }^{4}$ Documento técnico que orienta e norteia a gestão das áreas protegidas e identifica as necessidades locais. Apresenta o zoneamento estabelecido, as normas, as prioridades da UC, a organização de ações futuras, os programas que foram e serão desenvolvidos e as condutas administrativas para a UC (PARANÁ, 2002). 
suas respostas, as trocas de informações e as observações realizadas pelos outros integrantes do grupo incluíam novas informações e resultavam na aproximação ao objeto de observação. O percurso totalizava, em média, entre 1 hora e 40 minutos e 2 horas e 10 minutos, conforme a disponibilidade de tempo do grupo. As informações analisadas se referem às respostas dos visitantes a uma entrevista realizada no percurso da TI, com questões relacionadas a particularidades do ambiente e às observações aos sujeitos.

Esta pesquisa buscou investigar os fatores que promovem a percepção ambiental dos visitantes em uma TI e que podem resultar em aprendizagem socioambiental. Além disso, foi essencial descrever situações de uma visita a uma área de proteção ambiental na TI que contribuíram para que os visitantes pudessem desenvolver atitudes socioambientais. Para tanto foi necessário analisar os momentos em que a percepção dos visitantes foi alterada mediante um desequilíbrio cognitivo.

Esta investigação assenta-se no pressuposto de que é na superação da percepção que a construção do conhecimento se efetiva, e não na sensibilização, como sugerem muitos estudos de EA em ambientes naturais. A meta foi evidenciar que a interação sujeito-ambiente é necessária ao processo de aprendizagem socioambiental, porém, insuficiente se não for acrescida de conflito cognitivo.

A EA representa uma proposta educacional fundamentada em valores sociais voltados ao ambiente e surge da necessidade de detectar e responder aos problemas a que o ambiente foi exposto. A complexidade da EA está no processo, que trata não apenas do ambiente natural mas do ambiente social, que necessita promover uma ruptura paradigmática e sugere a revisão do pensamento científico. Dessa ruptura surge uma nova forma de aprender que envolve um processo na construção do conhecimento, interliga fatores sociais e ambientais na mesma dimensão e compreende uma ação interna do indivíduo, além de envolver questões éticas e morais. Por sua vez, a atitude socioambiental corresponde ao ato em si, ou seja, à capacidade de o indivíduo executar ações condizentes com essa construção.

O suporte teórico da pesquisa é permeado pelos campos da epistemologia e da psicologia de perspectiva piagetiana. Na epistemologia há o "estudo das relações entre o sujeito e objeto, bem como a passagem de um conhecimento menos estruturado para um conhecimento mais estruturado" e na psicologia há a "perspectiva de como os indivíduos se organizam para responder aos desafios do ato cognoscitivo" (ROSSO; BECKER; TAGLIEBER, 1998, p. 64). Com a epistemologia pretende-se a busca pela compreensão de como o objeto é descrito ou representado no processo de construção do conhecimento; com a psicologia busca-se o entendimento dessa construção e de como o sujeito se organiza para conhecer, isto é, das mudanças que ocorrem no indivíduo durante esse processo. 


\section{A construção do conhecimento à luz da psicologia e epistemologia genética}

A construção do conhecimento envolve aspectos que vinculam a organização e funcionamento intelectual do sujeito à apreensão do mundo à sua volta. O novo conhecimento será vinculado aos anteriores e os já adquiridos podem ser constantemente modificados, na medida em que se alteram os significados das experiências e organização cognitiva do sujeito. Essas sucessivas ligações entre o conhecimento novo e o anterior são sempre conhecimentos de aspectos da realidade com os quais se entrou em contato ao longo da vida por meio de experiência direta e das informações recebidas, e não de um dado "global e geral da realidade" (ROSSO; BERGER, 2006, p. 328).

A autorregulação integra os fatores em jogo nas experiências físicas e sociais com a organização e funcionamento do sujeito e constituem a equilibração (ROSSO, 1998). Esta, à medida que o sujeito se desenvolve intelectualmente e/ou avança na organização do conhecimento, ganha crescente independência do físico-social e das funções orgânicas do sujeito. Os avanços organizativos advindos da autorregulação se nutrem nos desequilíbrios, pois estes "obrigam o sujeito a superar-se na busca de um novo equilíbrio, conseguido com o auxílio das auto-regulações" (1998, p. 80).

A partir da Teoria da Equilibração de Piaget (FERREIRA, 2003), tem-se por princípio que o pensamento apresenta uma estrutura, evidenciando um sistema de gerações autorreguladas e autorreguladoras que permitem ao indivíduo assumir uma determinada ação ou conjunto de ações perante um problema concreto. A estrutura é de natureza cognitiva e representa uma forma de organização de seus processos em sistemas coerentes. As estruturas podem ser figurativas (percepção e ação mental) ou operatórias (estrutura de ação e de operação). A estrutura figurativa está subordinada à operatória e desenvolve um papel indicativo ou de representação dos estados (sistemas de significação ou de ações significativas).

A percepção envolve o duplo sentido de centração e descentração. A centração acontece no campo visual e representa o espaço percebido sem o movimento dos olhos e do corpo, correspondendo apenas à atividade visual; a descentração corresponde à exploração e ao movimento ocular (BATTRO, 1976). Isso sinaliza que a centração representa somente um episódio breve no conjunto das atividades perceptivas (FURTH, 1974). Piaget (1972) adverte que a centração é uma causa de deformação e a descentração atua como correção das centrações. É nesse particular que ocorrem os erros perceptivos, pois a ausência de descentração corresponde somente a um nível anterior e inferior à operação, e é a estrutura operatória que conduz a uma transformação (dedutível) com descentração.

Ao conceber a natureza da percepção, Piaget destaca dois momentos: a percepção como fonte de erros sistemáticos e como prefiguração indireta da inteligência. O primeiro, decorrente da centração, em que pode acontecer certa deformação do objeto, permanece no nível sensório-motor (egocentrismo). O 
segundo ultrapassa esse nível e se integra na construção cognitiva, no nível operacional conduzido pela descentração.

O egocentrismo cognitivo deriva da ausência de diferenciação entre o seu ponto de vista e outros possíveis. Piaget utiliza o termo egocentrismo como uma falta de habilidade inicial de descentralização. $O$ autor complementa que o egocentrismo suscita a noção de centração e descentração, ou seja, a habilidade de contemplar a realidade externa e os objetos como distintos de si mesmo e de um ponto de vista diferente do seu (PIAGET, 1983). Ele também explica que a redução gradual do egocentrismo se encontra na construção do mundo objetivo e na elaboração do raciocínio lógico.

Piaget (1978) apresenta como mito a questão de os conhecimentos procederem da abstração de dados sensoriais, negando a concepção empirista, e não a atividade do sujeito como simples registro de dados. $O$ estudioso considera ainda que a atividade do sujeito é inerente à percepção, porque presume uma organização da assimilação do objeto em esquemas prévios (PIAGET, 1974). O fundamento está na hipótese de que:

Nossos conhecimentos não provêm nem da sensação, nem da percepção somente, mas da ação inteira, cuja percepção constitui apenas função de sinalização. $O$ problema da inteligência não é realmente operatório. Portanto, as operações consistem em ações interiorizadas e coordenadas em estruturas de conjunto (reversíveis etc.) e se se quiser levar em conta este aspecto operatório da inteligência humana, é, pois, da própria ação e não da percepção apenas que convém partir. (PIAGET, 1978, p. 73).

Para Piaget (1978, p. 93), a inteligência não funciona como simples registro das ações, mas como um "progresso dos conhecimentos [...] indissociável entre a experiência e a dedução". Isso significa que a ação intelectual se caracteriza pelo ato de interiorização de determinado objeto que entra em conflito com as representações já formadas referentes a si mesmo, o que se deve ao fato de que, quando a ação é interiorizada pelo indivíduo, há o envolvimento do "aspecto ativo, atuante da inteligência, que transforma e modifica os dados que o indivíduo põe em ação ao conhecer" (ROSSO; BECKER; TAGLIEBER, 1998, p. 67).

Assim, pode ser verificado que existe a possibilidade de reestruturação do objeto conhecido por meio da sua problematização e dos mecanismos envolvidos e que "todas as formas de conhecimentos, como também a construção das estruturas mentais, dependem direta ou indiretamente da experiência do indivíduo com o meio físico ou social" (ROSSO, 1998, p. 89). Dessa forma, o conflito cognitivo associado à equilibração promove a aprendizagem e a passagem a novos estados de equilíbrio. As reequilibrações não se caracterizam pelo retorno do equilíbrio antecedente, mas, ao contrário, por formar um equilíbrio novo e mais perfeito. Isso o distingue dos equilíbrios mecânicos, que apenas se ajustam a uma perturbação e não têm condições de se modificar para gerar uma compensação completa. $O$ equilíbrio cognitivo é um 
sistema aberto que consegue elaborar formas com conteúdo exógeno (SISTO, 1993).

No processo adaptativo assimilação-acomodação, há a suposição da existência de desequilíbrios e a necessidade de equilibração, porque "a construção de um conhecimento novo não destr[ó]i o anterior, apenas e tão somente o integra" (SISTO, 1993, p. 41). O conflito cognitivo se constitui em uma das origens do desenvolvimento cognitivo. Nem todo desequilíbrio representa um papel formador, mas pode servir como desencadeador do processo de reequilibração, que, por sua vez, tem a função de aprimorar a forma anterior. Essa reequilibração produz uma equilibração majorante que "supõe construção, aprimoramento e quantificação das negações, uma coordenação mais precisa e a consolidação de um desenvolvimento" (SISTO, 1993, p. 42).

Desse modo, conforme o autor, a assimilação não acontece sem que os objetos apresentem resistência, a qual funciona como um obstáculo que é caracterizado como perturbação, a reação à perturbação, e cuja reação é denominada regulação. No entanto, nem toda perturbação ocasiona uma regulação. Quando é utilizado o conflito cognitivo, busca-se intervir no processo de regulação e têm-se duas alternativas: a produção de uma equilibração majorante, quando a ação inicial é ultrapassada e se chega a um equilíbrio mais vasto e mais constante e há indícios de operatoriedade; ou a ação inicial é estabilizada e enriquecida, o que caracteriza um processo construtivo.

Pensar uma TI na perspectiva piagetiana da construção do conhecimento é levar em consideração os fatores em jogo na construção do conhecimento, o papel dos desequilíbrios e da autorregulação e a percepção como um índice, como fator relativo e dependente da organização e funcionamento cognitivo do sujeito. Esses elementos constituirão o aporte teórico para a análise e confronto das informações coletadas no acompanhamento e orientação dos visitantes da UC do Parque Estadual do Guartelá.

\section{Procedimentos metodológicos}

A presente pesquisa é predominantemente qualitativa, com interfaces da pesquisa-ação (DUARTE, 2002; FRANCO, 2005; GONZALEZ; TOZONIREIS; DINIZ, 2007; TOZONI-REIS, 2005; TRIPP, 2005) com a pesquisa etnográfica (ANDRÉ, 1995; GHEDIN; FRANCO, 2008). Pesquisa-ação, pela preocupação do pesquisador com a transformação da realidade investigada; pesquisa etnográfica, por permitir o envolvimento do pesquisador com o universo pesquisado e a aproximação com os sujeitos ao tentar compreender as subjetividades.

A coleta de informações ocorreu mediante entrevista não diretiva (THIOLLENT, 1985) e observação com roteiro próprio. Na entrevista não diretiva buscaram-se respostas livres do entrevistado com a exploração de seus conhecimentos sobre o assunto. A observação também contribui para a identificação das características dos sujeitos, além de possibilitar ao pesquisador uma avaliação prévia das atitudes deles no processo de intervenção. 
A observação obedecia a um roteiro próprio e foi uma estratégia de intervenção que possibilitou verificar a ampliação do universo das respostas dadas pelos sujeitos. A estreita relação que o indivíduo estabelece entre a fala e os gestos pode mostrar para o pesquisador muito mais que informações, haja vista que facilita uma abertura no universo do sujeito. As expressões faciais, a pausa prolongada na fala, os gestos repentinos, os olhares dispersos ou atentos são algumas das situações observadas que contribuíram expressivamente para a análise das informações.

Para o estudo das informações foi empregada a análise de conteúdo temático-categorial (BARDIN, 1977) e a análise textual do software ALCESTE5 (CAMARGO, 2005; NASCIMENTO; MENANDRO, 2006). O objetivo da análise de conteúdo é compreender os emissores por meio do que é intrínseco aos seus enunciados. O tratamento das informações pelo software ALCESTE permite uma análise lexical de um conjunto de segmentos de texto, com uma dimensão quantitativa dos elementos textuais. A combinação da análise realizada por meio das categorias com a análise do relatório emitido pelo software possibilitou a triangulação das informações.

Ao realizarem um estudo sobre o software, Nascimento e Menandro (2006) apontam a estrutura do ALCESTE, que é baseado em cálculos efetuados em relação à ocorrência de vocábulos em segmentos de texto. Para os autores, o ALCESTE contribui para a sustentação de hipóteses do pesquisador porque, por meio da classificação objetiva e estatística dos termos lexicais, a análise do material proporciona informações confiáveis. Além disso, mostram que a análise de conteúdo precisa anteceder a análise do ALCESTE, visto que este último pode influenciar o primeiro agrupamento das categorias.

Ao apresentar o programa ALCESTE, Camargo (2005) explica suas principais características, os elementos que compõem o relatório e como proceder na leitura e análise do relatório. O autor evidencia que uma análise quantitativa de elementos textuais "não deixa de considerar a qualidade do fenômeno estudado, e ainda fornece critérios provenientes do próprio material para a consideração do mesmo como indicador de um fenômeno de interesse científico" (CAMARGO, 2005, p. 511).

O programa faz a leitura, classifica as palavras de acordo com suas ocorrências e as agrupa em classes. O material precisa ser organizado em um corpus, sendo cada entrevista uma unidade de contexto inicial (UCI). As UCIs são divididas em segmentos de texto que correspondem às unidades de contexto elementar (UCEs). Para realizar a análise, o programa executa quatro etapas. A etapa A consiste na leitura do texto e cálculo dos dicionários. Nessa etapa há três operações: a A1, que divide o texto em UCEs, a A2, que faz a pesquisa do vocabulário e reduz as palavras em radicais, e a A3, que gera um dicionário de formas reduzidas. $\mathrm{Na}$ etapa $\mathrm{B}$ acontece o cálculo das matrizes de dados e a classificação das UCEs. Essa etapa compreende as seguintes operações: a B1, que seleciona as UCEs a serem analisadas e faz um cálculo da matriz, a B2, que

${ }^{5}$ Análise Lexical pelo Contexto de um Conjunto de Segmentos de Texto. 
faz o cálculo das matrizes para a classificação hierárquica descendente (CHD), que se refere ao princípio da semelhança versus diferença, e a B3, que é a classificação hierárquica descendente $(\mathrm{CHD})$. A etapa $\mathrm{C}$ corresponde à descrição das classes. É responsável por ilustrar as relações entre as classes e para isso tem três operações: a C1 define as classes escolhidas, a C2 descreve as classes e a C3 realiza a análise fatorial de correspondência (AFC).

A última etapa se refere a cálculos complementares por meio dos quais o programa fornece as UCEs específicas de cada classe. Essa etapa possibilita uma contextualização do vocabulário específico de cada classe e contém quatro operações: a D1 seleciona as UCEs mais peculiares de cada classe; a D2 pesquisa por classe os segmentos repetidos; a D3 é a classificação hierárquica ascendente (CHA) e constrói matrizes de formas associadas a uma mesma classe versus as UCEs da classe associada; a D4 seleciona as palavras específicas das classes.

A análise foi realizada em 21 entrevistas que se constituíram em um corpus com 21 UCIs. No relatório fornecido pelo programa obteve-se um corpus com 149 UCEs selecionadas, e destas foram classificadas 107, o equivalente a $71,81 \%$ do total. Para a análise foram consideradas as palavras com frequência igual ou maior que 3 e o $\chi^{2}$ (qui ao quadrado) a partir de 3,84. O dendrograma na Figura 1 demonstra o resultado da classificação hierárquica descendente (CHD) e possibilita visualizar a estabilidade das classes. O corpus foi constituído de 4 classes ordenadas. Na primeira partição, evidencia-se uma oposição entre as classes 4, de um lado, e as classes 1, 2 e 3, de outro. A segunda partição separa a classe 2 das classes 1 e 3 , ao passo que a terceira partição diferencia as classes 1 e 3 entre si. As partições possibilitam a avaliação das relações entre as classes. As classes foram denominadas de acordo com o seu conteúdo e suas informações: Classe 1: Ação - a experiência do visitante em uma unidade de conservação; Classe 2: Inquietação - o cuidado do visitante em uma unidade de conservação; Classe 3: Sensibilização - a admiração do visitante em uma unidade de conservação; Classe 4: Avaliação - a integração visitante-unidade de conservação.

As UCEs são específicas de cada classe. Desse modo, elas possibilitam a interpretação do conjunto textual. A Figura 1 apresenta a descrição das classes a partir das UCEs interligadas no dendrograma. 
Figura 1. Dendrograma da CHD do corpus trilha.

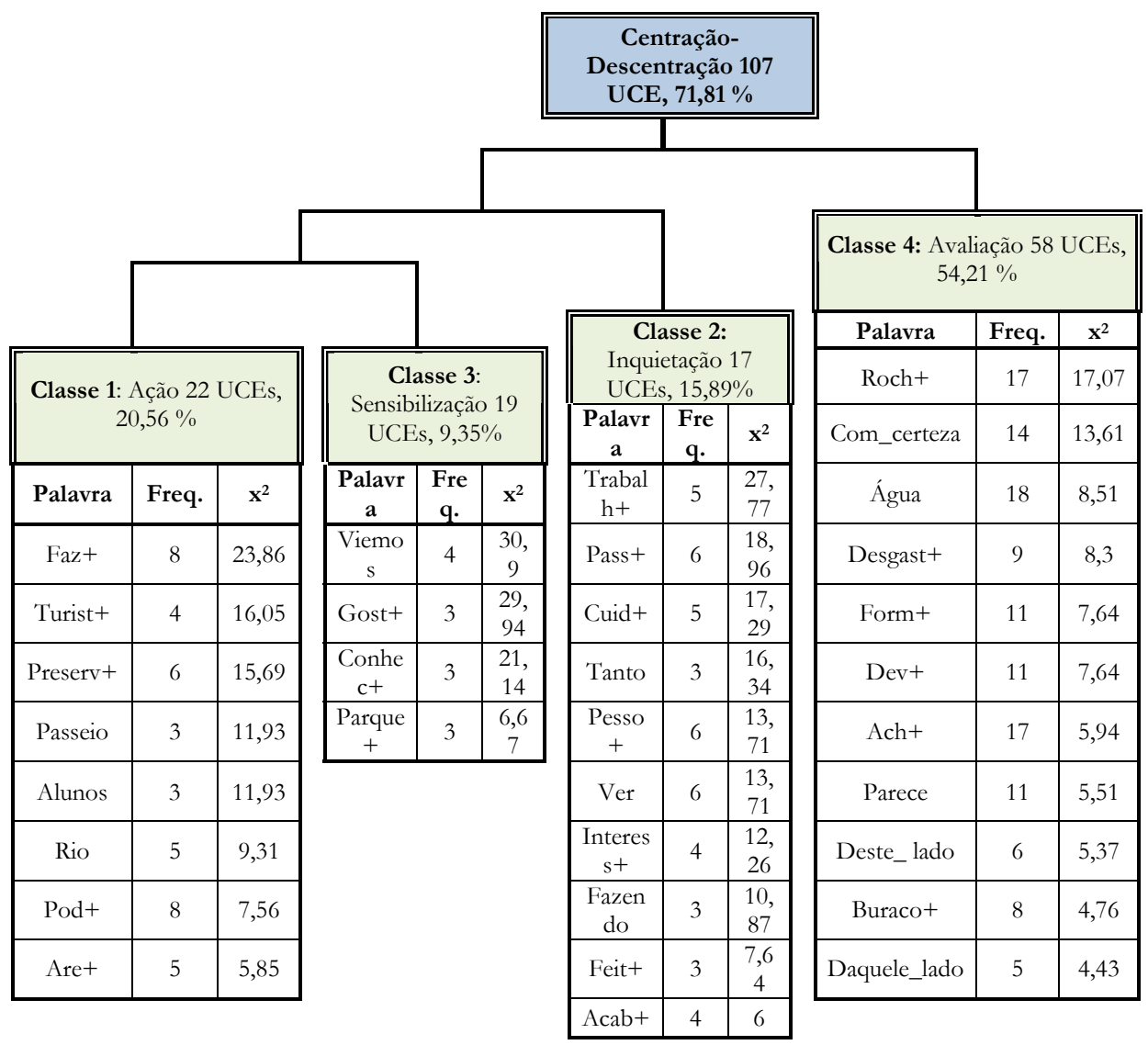

A classe um, denominada "Ação", traduz a experiência do visitante em uma unidade de conservação. As palavras-chave da classe são: faz+ (faz, fazemos e fazer), preserv + (preservação e preservando), pod + (pode, podem, podemos e podia) e rio. Os verbos fazer e poder indicam uma ação e nesse contexto estão ligados ao ambiente. Já os termos "rio" e preserv+ são inerentes ao ambiente. A leitura da etapa $\mathrm{D}$, mais especificamente da operação D1, demonstra que os vocábulos representam a atividade do sujeito enquanto visitante em uma UC.

$\mathrm{Na}$ operação D3 a relação entre os termos acontece da seguinte maneira: pod + está diretamente relacionado com faz + e preserv+; "rio' relaciona-se com preserv + ; preserv + relaciona-se com pod + e 'rio'. Assim, observa-se que o termo preserv+ é o núcleo dessa classe, pois já na operação D1 o vocábulo apresenta um número expressivo presente na classe 1 e na operação D3 apresenta ligação direta e indireta com os outros termos significativos dessa classe. A experiência dos visitantes nessa classe demonstra que praticaram uma ação concreta e partiram do pressuposto da própria atividade para responder às questões. 
Para ilustrar a expressividade das palavras, selecionamos algumas passagens de unidades em que elas aparecem. O ambiente como testemunho importante,

[...] até mesmo para eles saberem, porque sempre leem nos livros ou ouvem falar sobre [...] preservação, e aqui eles podem ver mais de perto o significado. (Ind_05). (Informações verbais ${ }^{6}$ ).

[...] este ambiente me traz um pouco do primitivo da história da formação geológica [...] uma natureza rústica, que transmite o primitivismo e me leva à era da formação disto aqui, busca bem os antepassados, os milhões de anos atrás. (Ind_10).

São olhares em busca do contato com o primitivo, o sonho de quem se afasta dos centros urbanos em busca da natureza em que

[...] aflora uma coisa mais primitiva do homem em contato com a natureza, associa uma sensação e uma coisa mais primitiva das nossas origens. Eu achei que é importante esse contato. (Ind_19).

A classe três, denominada "Sensibilização", traduz a admiração do visitante por uma unidade de conservação. As palavras-chave da classe são: conhec+ (conhecer), 'viemos', parque+ (parque e parques) e gost + (gostamos, gostaram e gosto). O programa não criou matriz para essa classe. Os termos indicam que o visitante busca conhecer a unidade de conservação e se mostra sensibilizado pelo ambiente.

Nessa classe é possível afirmar que a característica mais expressiva está na centração, que evidencia que o sujeito está centrado em si mesmo e em suas perspectivas. E, nesse processo, o indivíduo permanece em um estado no qual não ultrapassa a sensação, a sensibilização pelo ambiente, o que demonstra que o sujeito sensibilizado não interage com o ambiente, apenas desfruta de seus atrativos. Isso significa que o ambiente serve apenas como atrativo e representa uma possível fuga da vida urbana.

A classe evidencia a sensibilidade do visitante em uma área de proteção ambiental, como nos exemplos a seguir:

[...] gosto muito de lugar sossegado, e, se for para sair da sua cidade para ir até outra cidade, não tem muita novidade. (Ind_03).

O contato com a natureza e também o fato de estarmos conhecendo um lugar diferente, mas a importância mesmo está no contato com a natureza. Este ambiente desestressa porque é um ambiente sossegado. Onde moramos existem muitos parques, mas são diferentes, principalmente em relação à paisagem e ao verde. (Ind_17).

\footnotetext{
${ }^{6}$ Informações fornecidas pelos visitantes em entrevistas realizadas no percurso da TI do Parque
} Estadual do Guartelá, município de Tibagi/PR, em 2008. 
A classe dois, aqui chamada de "Inquietação", apresenta a preocupação do visitante em relação ao cuidado numa unidade de conservação. As palavras-chave da classe são: trabalh+ (trabalhando e trabalho), cuid+ (cuidado, cuidando, cuidar), pass+ (passa, passado, 'passam', 'passamos', 'passando', 'passar' e 'passassem'), pesso+ (pessoal e pessoas) e 'ver'. A operação D3 mostra que os vocábulos "ver" e cuid+ se relacionam diretamente, e os termos trabalh+e pass+ estão inter-relacionados aos dois primeiros. Já o termo pesso + se relaciona somente com cuid + . Nesse sentido, é óbvio que o visitante espera que as pessoas cuidem da unidade de conservação. O termo central dessa classe é trabalh+, voltado à preservação e cuidado do ambiente, de acordo com o conteúdo das UCEs presentes na classe.

Nessa classe, assim como na classe 1, pode-se dizer que os sujeitos apresentam uma compreensão do trabalho de preservação. Os sujeitos demonstram, pelas respostas dadas às questões, que o ambiente foi assimilado e transformado pelo próprio indivíduo. A partir dos questionamentos, surge a inquietação, ou seja, os sujeitos passaram a observar mais atentamente o ambiente. Esse processo evidencia que é possível, por meio da provocação, ou seja, do questionamento ao visitante, aproximá-lo do ambiente, o que contribui para o enriquecimento de informações problematizadas pelo próprio visitante. Aqui aparece o avanço cognitivo do visitante mediado pela problematização do guia.

A classe demonstra uma preocupação por parte do visitante em relação ao ambiente, como

[...] conhecer lugares preservados e a história destes locais, além de poder sair da cidade e fugir do estresse. Acompanhar o trabalho que está sendo feito para a preservação, ver que tem pessoas que se interessam em preservar e saber que alguém está cuidando deste patrimônio. (Ind_13).

Tem a trilha, mas é um mal necessário, porque senão o pessoal iria andar por qualquer lugar e iria acabar danificando mais ainda [...] o ambiente nunca mais será o mesmo a partir do momento em que aconteceu alguma interferência neste lugar, nunca mais vai ser igual. Mas as pessoas estão respeitando o local, não estão destruindo tanto, mas não é possível cuidar de todo mundo, então, vai da consciência de cada um. (Ind_14).

A quarta classe, denominada "Avaliação", traduz a integração visitanteunidade de conservação. As palavras mais expressivas nessa classe são: água, roch+ (rocha, rochas e rochosas), form+ (forma, formada, formando, formar e formou), buracos + (buraco e buracos), com certeza e parece. A operação D3 é a mais extensa e também a mais rica de relações: o termo água está diretamente relacionado às palavras "parece" e "com certeza"; o vocábulo roch + se relaciona ao termo "com certeza"; a palavra buraco está relacionada ao termo "água"; entre esses se encontra dev+ e o termo form+ está ligado à palavra "buraco". A palavra central dessa classe é "água", o que demonstra que os sujeitos atribuem 
ao termo a responsabilidade pelas transformações que aconteceram no ambiente. Nessa classe estão presentes 58 UCEs, que representam 54,21\% do total do corpus. É a classe mais expressiva e a que demonstra a capacidade de observação e interpretação dos sujeitos.

A partir da leitura e interpretação da operação D1, torna-se evidente que a classe 4 demonstra que os sujeitos, pelas respostas dadas, apresentam um esforço de descentração, pois predomina nas respostas o esforço mental que realizam para se posicionarem de acordo com outro ponto de vista, ou seja, olham novamente para o ambiente e reordenam seus pensamentos antes de expressarem uma resposta. Essa afirmativa também é corroborada pelos registros das observações feitas enquanto os sujeitos se deslocavam pela TI.

A classe apresenta a integração visitante-unidade de conservação a partir da avaliação que o sujeito faz ao responder às questões:

O lado de lá tem muita mata, muitas árvores, e aqui está meio desmatado. Fora isso, ninguém chegou lá perto ainda, ou chegou e não fez estrago nenhum. (Ind_20).

[...] deste lado a vegetação é muito mais aberta e já está mais degradada, porque tem o contato com o ser humano, daquele lado a mata está mais preservada e mais fechada; daquele lado, tem mata fechada, deste lado não. (Ind_16).

Aqui tem erosão também; lá também teve erosão, mas tem mais mata fechada. (Ind_09).

É diferente por causa do fluxo de pessoas que ficam circulando aqui, e os animais podem ter se deslocado para o lado de lá. E aquele lado parece ter mais montanhas, mais rochas do que este lado. Foi formada pelo desgaste da água. (Ind_14).

As classes um, dois e três traduzem uma visão centrada da percepção do ambiente, expressa no desejo de desfrutar uma bela paisagem como um dos principais motivos que trazem os visitantes a uma UC. Já nas classes dois e quatro o sentido é diferente e recebe a contribuição do trabalho dos educadores ambientais para a construção de uma nova percepção socioambiental, avançando na superação do fazer e do perceber iniciais.

A educação contribui para o desenvolvimento do sujeito como ser social e para a construção das estruturas mentais. Nesse sentido, o papel do educador é imprescindível para gerar situações, preparar os dispositivos iniciais e suscitar problemas ao sujeito a fim de instigá-lo a resolvê-los e, em seguida, formular contra-exemplos que promovam a reflexão e provoquem o domínio de soluções precipitadas. Para tanto Piaget propõe os métodos ativos de ensino, que têm como principal fundamento a experimentação, porque

[...] uma experiência que não seja realizada pela própria pessoa, com plena liberdade de iniciativa, deixa de ser, por definição, uma experiência, transformando-se em simples adestramento, destituído de valor formador por falta da compreensão suficiente dos pormenores das etapas sucessivas. (PIAGET, 1984, p. 17). 
A reflexão é inerente à ação e à experiência, e estas não podem se dissociar no pensamento por comporem uma unidade essencial na aprendizagem. $\mathrm{O}$ pensamento é ativo quando o indivíduo se interessa e é afetado pelo objeto de conhecimento. Os métodos ativos se distinguem pela relação dinâmica entre sujeito e objeto, mediada por experiências significativas que viabilizam a ação intelectual e transformações cognitivas (ROSSO; TAGLIEBER, 1992). Assim, uma TI possui elementos representativos do próprio meio que o sujeito pode ser provocado a observar e na sua problematização encontrar ou elaborar conceitos sobre o ambiente e as interações dos humanos com o ambiente. Essa observação e essa problematização representam a experiência ativa, porque o sujeito não foi direcionado a uma resposta, ele pode chegar, por si mesmo, às mais diversas conclusões e relações homem-natureza.

A interação sujeito-meio ambiente na TI proporciona a aprendizagem como "desenvolvimento interno de representação de uma realidade que é percebida como algo externo e independente do agente cognitivo" (COLOM, 2004, p. 146). Isso sugere que o visitante, ao caminhar pela trilha, entra em contato com novos elementos que, ao serem observados, podem viabilizar a problematização do meio de acordo com a sua capacidade interpretativa, posto que "só se aprende se o sujeito é quem cognitivamente consegue, a partir da complexidade, interpretar e ordenar o conhecimento" (COLOM, 2004, p. 156). Assim, o conhecimento é construído a partir da experiência que o visitante vivencia na trilha.

Para a análise de conteúdo as categorias foram divididas de acordo com os conteúdos indicados por temáticas, tendo cada temática apresentado uma especificidade. Para aprofundar a análise da percepção do sujeito em relação ao ambiente, apresenta-se a Tabela 1.

Tabela 1. Resultado da análise das categorias.

\begin{tabular}{|c|c|c|c|}
\hline \multicolumn{2}{|c|}{$\begin{array}{c}\text { CENTRAÇÃO - EGOCENTRISMO E } \\
\text { SENSIBILIZAÇÃO }\end{array}$} & \multicolumn{2}{|c|}{$\begin{array}{c}\text { DESCENTRAÇÃO - DESEQUILÍBRIO } \\
\text { COGNITIVO }\end{array}$} \\
\hline Categorias & Temáticas & Categorias & Temáticas \\
\hline $\begin{array}{c}\text { Motivação para visitar } \\
\text { uma unidade de } \\
\text { conservação }\end{array}$ & $\begin{array}{l}\text { - Higiene mental } \\
\text { - Contemplação }\end{array}$ & $\begin{array}{c}\text { Motivação para visitar } \\
\text { uma unidade de } \\
\text { conservação }\end{array}$ & $\begin{array}{l}\text { - Conhecer o ambiente } \\
\text { - Ambiente educativo }\end{array}$ \\
\hline $\begin{array}{c}\text { Representações da UC } \\
\text { pelo visitante }\end{array}$ & $\begin{array}{l}\text { - Sensações agradáveis } \\
\text { - Patrimônio }\end{array}$ & $\begin{array}{l}\text { Representações da UC } \\
\text { pelo visitante }\end{array}$ & $\begin{array}{l}\text { - Ambiente nativo, } \\
\text { histórico e educativo. }\end{array}$ \\
\hline $\begin{array}{c}\text { Interpretações a partir } \\
\text { das percepções do } \\
\text { ambiente }\end{array}$ & - Centração & $\begin{array}{c}\text { Interpretações a partir } \\
\text { das percepções do } \\
\text { ambiente }\end{array}$ & $\begin{array}{l}\text { - Ambiente protegido } \\
\text { - Interferência humana } \\
\text { - Processos naturais que } \\
\text { influenciam o ambiente } \\
\text { - Ação da água e do } \\
\text { tempo } \\
\text { - Diferentes tipos de } \\
\text { rochas }\end{array}$ \\
\hline $\begin{array}{l}\text { Interpretação a partir da } \\
\text { avaliação da percepção } \\
\text { do ambiente }\end{array}$ & $\begin{array}{l}\text { - A ponte como } \\
\text { patrimônio } \\
\text { - Ambiente conservado }\end{array}$ & $\begin{array}{l}\text { Interpretação a partir da } \\
\text { avaliação da percepção } \\
\text { do ambiente }\end{array}$ & $\begin{array}{l}\text { - A visitação como } \\
\text { interferência negativa } \\
\text { - Rochas desgastadas pela } \\
\text { ação humana } \\
\text { - Cumprimento das } \\
\text { normas }\end{array}$ \\
\hline
\end{tabular}


A percepção está vinculada a aspectos do mundo externo e a suas características efêmeras, que se modificam continuamente, ao mesmo tempo que seu desenvolvimento pleno é somente uma manifestação da inteligência. Assim, temos que não existe percepção sem conhecimento operativo, pois Piaget "só fala em percepção quando o aspecto figurativo forma parte integrante do conhecimento e quando o objeto do conhecimento está imediatamente presente para os sentidos" (FURTH, 1974, p. 163). A atividade perceptiva equivale ao ato cognitivo, que implica percepção. A partir desse pressuposto, evidencia-se, em relação às categorias, que os elementos que se mostraram mais expressivos para os sujeitos são representados pelas temáticas em que foi necessário estabelecer uma ação. Além disso, a centração nas temáticas está acompanhada da sensibilização e também da dificuldade do sujeito em se posicionar em relação ao outro. Já a descentração, nas temáticas, mostra que os visitantes estabeleceram um conflito cognitivo ao construírem suas respostas, o que representa um desequilíbrio, ou seja, pela compreensão dos fenômenos se extrai o conhecimento.

A categoria "motivação para visitar uma unidade de conservação" possibilita avaliar, por inferência, o que os visitantes buscam no ambiente natural. $\mathrm{Na}$ categoria "representações da UC pelo visitante" evidencia-se o modo como o sujeito "experimenta" o ambiente, de acordo com suas próprias expectativas. A categoria "interpretações a partir das percepções do ambiente" revelou-se o conjunto de respostas mais significativo, já que somente uma temática permaneceu na centração; as demais exigiram dos sujeitos a interação com o ambiente. Além disso, foi possível verificar que os sujeitos aproveitavam a própria experiência de uma questão para complementar a outra. Essa categoria possibilitou uma análise mais profunda, mesmo se sabendo que a observação do visitante em relação ao ambiente foi elemento fundamental em todas as questões, servindo de base para esse conjunto. Algumas das questões não possibilitavam as respostas sem os sujeitos observarem novamente o ambiente, o que fez com que muitos deles demonstrassem um aprendizado construído por si próprios.

A categoria "interpretação a partir da avaliação da percepção do ambiente" expressou a avaliação do processo de visitação. Isso se deve ao fato de que, para responder à última questão, o visitante refazia mentalmente o percurso completo da trilha. Verificamos que os sujeitos que se sensibilizaram muito com o ambiente não conseguiram perceber nenhum impacto no local.

$\mathrm{Na}$ análise do relatório ALCESTE as respostas mais significativas vieram de sujeitos que foram além das questões e conseguiram entender o impacto que eles, como visitantes, causam no ambiente. Isso não aconteceu com os demais sujeitos, que direcionam a responsabilidade para os visitantes sem considerarem que eles próprios são visitantes e, de certa forma, estão provocando alguma interferência no ambiente. No entanto, concorda-se com ind_11 quando observa o "impacto natural de qualquer parque onde existe uma trilha para turistas; se não quiser impacto negativo, você vai ficar com o parque fechado". 
A análise a partir do relatório do software ALCESTE permitiu reafirmar o que já havia sido previsto, isto é, que a sensibilização nem sempre possibilita ao sujeito descentrar-se.

Tabela 2. Resultado da análise das classes do relatório emitido pelo software ALCESTE.

\begin{tabular}{|c|c|}
\hline $\begin{array}{c}\text { SENSAÇÃO - SENSIBILIZAÇÃO } \\
\text { CENTRAÇÃO }\end{array}$ & $\begin{array}{c}\text { DESCENTRAÇÃO - CONFLITO } \\
\text { COGNITIVO - APRENDIZAGEM }\end{array}$ \\
\hline $\begin{array}{c}\text { Classe 3: Sensibilização } \rightarrow \text { Centração - } \\
\text { efeito de campo }\end{array}$ & Classe 1: Ação $\rightarrow$ Assimilação - atividade lógica \\
& Classe 2: Inquietação $\rightarrow$ Assimilação - atividade lógica \\
& Classe 4: Avaliação $\rightarrow$ Descentração $\rightarrow$ aprendizagem \\
\hline
\end{tabular}

Fonte: Machado, 2009, p. 95.

Constatou-se que na classe 3, a partir do próprio conteúdo da classe, os sujeitos não se esforçavam para elaborar suas respostas. Além disso, tanto o conteúdo dessas respostas como os registros de observação evidenciam que o sujeito permaneceu em uma situação de centração, o que não acontece em relação à classe 4 , em que os indivíduos expressaram, pelas respostas dadas, uma atividade perceptiva descentrada. A classe 1 demonstra que o visitante responde às questões pela experiência que realiza e a classe 2 evidencia que o indivíduo visita uma área de proteção ambiental com a preocupação de interferir o menos possível no ambiente. Nessas duas classes os sujeitos apresentam uma atividade lógica, a assimilação do ambiente.

É a partir do conflito cognitivo que o visitante acrescenta uma nova informação, conseguindo ou não reconstruir seus conhecimentos. Desse modo, avaliam-se como possível conflito os momentos em que os sujeitos eram questionados e olhavam novamente para o ambiente, como se quisessem desvelá-lo. O olhar e a pausa na fala respondiam a uma de nossas questões: como as percepções dos visitantes em relação ao ambiente podem integrar e promover desequilíbrios cognitivos na aprendizagem de atitudes socioambientais?

Afirma-se isso por meio dos registros de observação, em que foi possível captar momentos em que os sujeitos (cabe ressaltar que não foram todos) voltavam o olhar para o ambiente, e era como se passasse um filme em suas mentes, e prosseguiam tentando organizar uma resposta. Alguns se valiam de experiências em outros locais e acrescentavam outras informações. Em cada questão da entrevista, ao final, buscou-se evidenciar aos sujeitos as possibilidades educativas daquele ambiente e que o próprio visitante pode e consegue, quando instigado, transformar um simples passeio em um evento repleto de potenciais educativos.

O termo socioambiental é utilizado para enfatizar o envolvimento entre as dimensões sociais e ambientais, segundo o Programa Nacional de Educação Ambiental - ProNEA (BRASIL, 2005). A partir disso, há uma ampliação na possibilidade educativa, embora a educação, por si, já remeta à necessidade de problematizar as questões que envolvem o indivíduo, o meio e a sociedade. 
Nisso a aprendizagem socioambiental equivale às atitudes dos sujeitos em relação ao meio em que vivem, viabilizada por fatores que promovem o êxito de sua concepção. Há a necessidade de o indivíduo possuir ou desenvolver um sentimento de pertencimento ao ambiente em que está inserido e, sobretudo, o comprometimento com o grupo social do qual faz parte.

Assim, integrar as crenças, atitudes e valores ambientais em programas de educação ambiental é fundamento essencial na construção de atitudes (GÓMEZ; ROSALES, 2000). As atitudes precisam ser desenvolvidas como um compromisso com a sociedade, e não somente como uma moral privada ou voltada exclusivamente ao ambiente. Por sua vez, as atitudes sempre dizem respeito a valores, que conquistam o lugar mais elevado e também abstrato na estrutura cognitiva do sujeito. Além disso, os autores defendem que os valores representam um papel importante no desenvolvimento da personalidade do indivíduo por intermédio da construção de uma hierarquia de valores que determinarão sua conduta e orientarão suas atitudes em sociedade.

O ambiente possui caráter sociológico, e não biológico; está inserido num todo que envolve processos de ordem física e social, porém, submetido ao domínio do poder econômico (LEFF, 2006). O ambiente se manifesta como resultado das configurações de conhecimento do mundo e também é influenciado pela coisificação da realidade e da natureza. Nesse sentido, a EA faz parte de um processo que instiga a capacidade do sujeito a relacionar seu conhecimento pessoal com o meio em que vive mediante um pensamento crítico (LEFF, 2004).

O saber ambiental equivale à problematização do ambiente, sem excluir as características próprias das ciências distintas, pois o ambiente é influenciado pelo contexto (LEFF, 2006). O conhecimento é resultante do saber ambiental e é aberto à produção de novas acepções civilizatórias, o que orienta a necessidade da desconstrução da racionalidade constitutiva do mundo. O saber ambiental problematiza o conhecimento com o objetivo de rever os processos econômicos e tecnológicos e propõe uma revisão nos processos culturais e produtivos.

\section{Considerações finais}

Nas intervenções que aconteceram entre os meses de maio e agosto de 2008, observou-se que no início da trilha os visitantes se mostravam dispersos no grupo. No entanto, com a intervenção do pesquisador, que os provocava a responder a questões sobre características próprias do ambiente, houve uma mudança significativa na forma como os sujeitos observavam o ambiente e interagiam no grupo.

Por meio da transcrição das entrevistas, foi possível captar momentos que não tinham sido registrados e acrescentá-los. Além disso, a abordagem aconteceu seguindo alguns critérios, como: deixar o visitante seguir seu ritmo, enquanto o pesquisador caminha na sua companhia; fazer as questões de forma clara e esperar que o indivíduo se pronuncie; antes de fazer as perguntas, deixar que o visitante se integre ao ambiente; não interromper o sujeito na construção de suas 
respostas; após observar que o sujeito esgotou suas respostas, acrescentar as informações sobre o que foi questionado. Com a análise das informações foi possível explorar a capacidade de interação sujeito-objeto, uma vez que a palavra emitida constitui um universo repleto de interpretações e significados. Essa interação evidencia ou não a transformação de uma ação em uma operação.

A contribuição educacional da pesquisa se configurou na capacidade que o sujeito, ao visitar uma área de proteção ambiental, pode vir a desenvolver por meio da experiência individual na problematização do ambiente, ou seja, relacionar aspectos socioculturais ao ambiente, dotando este último de conceitos enriquecidos com as experiências anteriores, num esforço de aceitar ou transformar o elemento que se impõe. Para tanto é o monitor que, mesmo estando em seu "ponto estratégico", pode se aproximar do visitante e questionálo sobre o ambiente, tentar provocá-lo a observar mais detalhadamente as características peculiares do local. Assim, a partir do questionamento feito pelo voluntário, o visitante vai “olhar" novamente o ambiente e tentar extrair deste a resposta. Esse simples gesto pode vir a possibilitar a atividade perceptiva do visitante e fazer com que ele observe e problematize aspectos antes não visualizados.

O referencial teórico teve ênfase nos aspectos ligados à construção do conhecimento. Assim, no material analisado, as expectativas centraram-se na apreensão do indivíduo em relação ao objeto. Buscou-se evidenciar a possibilidade de a percepção ser o ícone desencadeador de processos mentais capazes de estruturar uma aprendizagem por meio de um desequilíbrio provocado por conflito cognitivo.

O conflito desencadeia processos que, ao serem organizados pelo indivíduo, acrescenta informações necessárias ao desenvolvimento cognitivo. Fazem parte desse procedimento principalmente os fatores que estimulam ramificações capazes de promover a reconstrução do conhecimento já adquirido. As novas aquisições somam-se às antigas, integrando um conhecimento modificado ou novo.

De todo esse processo fazem parte os esquemas de conhecimento que o sujeito possui e reestrutura, bem como a adaptação (assimilação e acomodação) e o desequilíbrio, que provocam a equilibração das estruturas cognitivas. Todos os elementos que pressupõem essa atividade se configuram na capacidade de o indivíduo acrescentar uma informação nova ou reestruturar uma já adquirida e acrescentá-la à percepção. O visitante chega ao parque com a expectativa de receber mais informações sobre a visita, e, por falta dessas, nem sempre observa características importantes do ambiente.

A questão central que norteou todo o processo de investigação foram as contribuições que a visita a uma UC pode apresentar para viabilizar a aprendizagem socioambiental dos visitantes. Nesse sentido, tem-se que a trilha, assim como o próprio ambiente, é educativa. No entanto, há a necessidade de uma pessoa, não para acompanhar e narrar, mas para provocar o indivíduo a pensar e se posicionar com uma opinião ou afirmação quanto ao próprio entendimento em relação ao objeto problematizado. 
A contribuição está no significado que esse objeto passa a representar para o sujeito após ser desvelado por ele mesmo, e a aprendizagem se configura na experiência de observar e entender as implicações históricas, ambientais e culturais que estão presentes no processo.

A experiência ativa do sujeito equivale ao processo de aproximação do visitante com o ambiente. No momento em que é provocado a se posicionar como sujeito, o indivíduo passa a prestar mais atenção no que está à sua volta. A partir desse momento, faz associações e referências a experiências anteriores e estabelece um juízo para decifrar as causas que provocaram as transformações no ambiente.

Quanto à interação visitante-ambiente, a prática que foi desenvolvida possibilitou aos sujeitos várias tentativas de reorganização do pensamento. No momento em que eram questionados, isso ficou evidente por meio de sua fala ou dos gestos, do silêncio prolongado e, mais representativo, do olhar lançado novamente ao ambiente. As respostas eram construídas cuidadosamente e várias vezes modificadas.

Este estudo possibilitou comprovar que a TI possui um grande potencial educativo, não se restringindo a simples atividades de sensibilização. Mais ainda, foi comprovado que os sujeitos que mais se mostraram sensibilizados com o ambiente nem sempre foram os que mais problematizaram o ambiente.

\section{Agradecimento}

Agradecemos o apoio dado pelas seguintes agências financiadoras: CAPES DS, CNPq e Fundação Araucária.

\section{Referências}

ANDRÉ, Marli Elisa Dalmazo Afonso de. Etnografia da prática escolar. Campinas: Papirus, 1995.

BARDIN, Laurence. Análise de conteúdo. Tradução de Luís Antero Reto e Augusto Pinheiro. Lisboa: Edições 70, 1977.

BATTRO, Antonio M. O pensamento de Jean Piaget: psicologia e epistemologia. Tradução de Lino de Macedo. Rio de Janeiro: Forense Universitária, 1976.

BRASIL. Programa Nacional de Educaşão Ambiental - ProNEA. 3. ed. Brasília: MMA, 2005. . Instituto Brasileiro do Meio Ambiente e Recursos Naturais Renováveis IBAMA. As categorias de unidades de conservação brasileiras. Disponível em: <http://www.redeprouc.org.br/unidades.asp>. Acesso em: 16 dez. 2007.

BRITO, Angela Xavier de; LEONARDOS, Ana Cristina. A identidade das pesquisas qualitativas: construção de um quadro analítico. Cadernos de Pesquisa, n. 113, p. 7-38, jul. 2001. 
CAMARGO, Brigido Vizeu. ALCESTE: Um programa informático de análise quantitativa de dados textuais. In: MOREIRA, Antônia Silva Paredes; CAMARGO, Brigido Vizeu; JESUÍNO, Jorge Correia; NÓBREGA, Sheva Maia (Org.). Perspectivas teórico-metodológicas em representações sociais. João Pessoa: Editora da UFPB, 2005. p. 511-539.

COLOM, Antoni J. A (des) construção do conhecimento pedagógico: novas perspectivas para a educação. Porto Alegre: Artmed, 2004.

DUARTE, Rosália. Pesquisa qualitativa: reflexões sobre o trabalho de campo. Cadernos de Pesquisa, n. 115, p. 139-154, mar. 2002.

FERREIRA, Henrique da Costa. A teoria piagetiana da equilibração e as suas conseqüências educacionais. Bragança, Portugal: Estudos, 2003. p. 07-25.

FONTENELE JÚNIOR, Armando Matos. Percepção socioambiental: A visão de turistas e residentes de Guaramiranga - CE. 2004. 108 f. Dissertação (Mestrado em Desenvolvimento e Meio Ambiente) - Universidade Federal do Ceará, Fortaleza, 2004.

FRANCO, Maria Amélia Santoro. Pedagogia da pesquisa-ação. Educação e Pesquisa, v. 31, n. 3, p. 483-502, set./dez. 2005. Disponível em: <http://www.redalyc.org>. Acesso em: 17 set. 2008 às $9 \mathrm{~h}$

FURTH, Hans G. Piaget e o conhecimento: fundamentos teóricos. Tradução de Valérie Rumjanek. Rio de Janeiro: Forense Universitária, 1974.

GHEDIN, Evandro; FRANCO, Maria Amélia Santoro. Questões de método na construção da pesquisa em educação. São Paulo: Cortez, 2008.

GÓMEZ, Javier García; ROSALES, Julio Nando. Estrategias didácticas en educación ambiental. Málaga: Algibe, 2000.

GONZALEZ, Luciana Thais Villa; TOZONI-REIS, Marília Freitas de Campos; DINIZ, Renato Eugênio da Silva. Educação ambiental na comunidade: uma proposta de pesquisa-ação. Revista Eletrônica Mestrado em Educação Ambiental, v. 18, p. 379-398, jan./jun. 2007.

LEFF, Enrique. Epistemologia ambiental. Tradução de Sandra Valenzuela; revisão técnica de Paulo Freire Vieira. 4. ed. São Paulo: Cortez, 2006.

Saber Ambiental: sustentabilidade, racionalidade, complexidade, poder. 3. ed. Tradução de Lúcia Mathilde Endlich Orth. Petrópolis, RJ: Vozes, 2004.

MACHADO, Bernadete. A aprendizagem socioambiental dos visitantes em Unidades de Conservação. 2008. Dissertação (Mestrado em Educação) - Universidade Estadual de Ponta Grossa, Ponta Grossa, 2009.

MENGHINI, Fernanda Barbosa. As trilhas interpretativas como recurso pedagógico: caminhos traçados para a educação ambiental. 2005. Dissertação (Mestrado em Educação) Universidade Vale do Itajaí, Itajaí, 2005.

NASCIMENTO, Adriano Roberto Afonso do; MENANDRO, Paulo Rogério Meira. Análise lexical e análise de conteúdo: uma proposta de utilização conjugada. Estudos e Pesquisas em Psicologia, v. 6, n. 2, p. 72-88, jul./dez. 2006.

PARANÁ, Governo do. Instituto Ambiental do Paraná - IAP. Plano de Manejo do Parque Estadual do Guartelá. Curitiba - PR, 2002. 
PIAGET, Jean. Psicologia da inteligência. 2. ed. Tradução de Egléa de Alencar. Rio de Janeiro: Fundo de Cultura, 1972.

- Psicologia e Epistemologia: por uma teoria do conhecimento. Tradução de Agnes Cretella. 2. ed. Rio de Janeiro:Forense, 1978.

- A epistemologia genética; Sabedoria e ilusões da filosofia; Problemas de psicologia genética. Traduções de Nathanael C. Caixeiro, Zilda Abujamra Daeir, Célia E. A. Di Piero. 2. ed. São Paulo: Abril Cultural, 1983. (Coleção Os Pensadores).

- Para onde vai a educação? Tradução de Ivete Braga. 8. ed. Rio de Janeiro: José Olympio, 1984.

PIAGET, Jean; GRÉCO, Pierre. Aprendizagem e conhecimento. Tradução da equipe da Livraria Freitas Bastos. Rio de Janeiro: Freitas Bastos, 1974.

PIMENTA, Selma Garrido. Pesquisa-ação crítico-colaborativa: construindo seu significado a partir de experiências com a formação docente. Educação e Pesquisa, v. 31, n. 3, p. 521-539, set./dez. 2005.

ROSSO, Ademir José. A correlação no contexto do ensino de Biologia: implicações psicopedagógicas e epistemológicas. 1998. 208 f. Tese (Doutorado em Educação) Universidade Federal de Santa Catarina, Florianópolis, 1998.

ROSSO, Ademir José; BECKER, Fernando; TAGLIEBER, José Erno. A produção do conhecimento e a ação pedagógica. Educação e Realidade, v. 23, n. 2, p. 63-82, jul./dez. 1998.

ROSSO, Ademir José; BERGER, Maria Virgínia Bernardi. Esquemas de conhecimento: um dos caminhos para acessar a subjetividade docente. Contrapontos, v. 6, n. 2, p. 319-337, maio/ago. 2006.

ROSSO, Ademir José; TAGLIEBER, José Erno. Métodos ativos e atividades de ensino. Perspectiva, v. 17, p. 37-46, 1992.

SAMPAIO, Shaula Maíra Vicentini de; GUIMARÃES, Leandro Belinaso. Educação ambiental: tecendo trilhas, escriturando territórios. In: ENCONTRO DE PESQUISA EM EDUCAÇÃO AMBIENTAL, 4., 2007, Rio Claro, SP. Anais... Rio Claro: Unesp, 2007. p. 01-16.

SISTO, Fermino Fernandes. Fundamentos para uma aprendizagem construtivista. ProPosições, v. 4, n. 2, p. 38-52, 1993.

SOUZA, Alex Francisco de; PRADO, Fabio de Oliveira. Programa de educação ambiental realizado pelo Parque Estadual do Morro do Diabo. In: ENCONTRO PARANAENSE DE EDUCAÇÃO AMBIENTAL, 10., 2007, Maringá. Anais... Maringá: UEM, 2007. p. 1-10.

TABANEZ, Marlene Francisca; PADUA, Suzana Machado; SOUZA, Maria das Graças de; CARDOSO, Marli Maria; GARRIDO, Leda Maria do Amaral Gurgel. Avaliação de trilhas interpretativas para Educação Ambiental. In: PADUA, Suzana Machado; TABANEZ, Marlene Francisca (Org.). Educação Ambiental: Caminhos Trilhados no Brasil. Brasília: Instituto de Pesquisas Ecológicas, 1997. p. 89-102.

THIOLLENT, Michel J. M. Crítica metodológica, investigação social e enquete operária. 4. ed. São Paulo: Polis, 1985. 
TOZONI-REIS, Marília Freitas de Campos. A construção coletiva do conhecimento e a pesquisa-ação-participativa: compromissos e desafios. In: ENCONTRO DE PESQUISA EM EDUCAÇÃO AMBIENTAL, 3., 2005, Ribeirão Preto, SP. Disponível em: <http://www.dscomunicacao.com.br/teia/Biblio01/31\%20PA $\% 20$ Pesquisa $\%$ E7ao $\% 20$ Participativa-\%20Marilia.doc>. Acesso em: 02 jul. 2008 às $11 \mathrm{~h}$.

TRIPP, David. Pesquisa-ação: uma introdução metodológica. Tradução de Lólio Lourenço de Oliveira. Educação e Pesquisa, São Paulo, v. 31, n. 3, p. 443-466, set./dez. 2005.

TROGELlO, Anderson Giovani; POLINARSKI, Celso Aparecido. Caminhada no meio da mata: relato de experiência geradora de educação ambiental. In: ENCONTRO PARANAENSE DE EDUCAÇÃO AMBIENTAL, 10., 2007, Maringá. Anais... Maringá: 2007. p. 1-11.

Artigo recebido em 31/1/2011 e aprovado em 22/8/2011. 